\title{
Electrodeposition of Some Selective Metals Belonging to Light, Refractory and Noble Metals from lonic Liquid Electrolytes
}

\author{
Bonita Dilasari, Kyungjung Kwon*, Churl Kyoung Lee", and Hansu Kim ${ }^{\dagger \dagger}$ \\ Department of Energy \& Mineral Resources Engineering, Sejong University, Seoul 143-747, Korea \\ ${ }^{\dagger}$ School of Advanced Materials \& Systems Engineering, Kumoh National Institute of Technology, \\ Gumi, Gyungsangbuk-do 730-701, Korea \\ ¥Department of Energy Engineering, Hanyang University, Seoul 133-791, Korea
}

(Received July 23, 2012 : Accepted August 30, 2012)

\begin{abstract}
Ionic liquids are steadily attracting interests throughout a recent decade and their application is expanding into various fields including electrochemistry due to their unique properties such as non-volatility, inflammability, low toxicity, good ionic conductivity, wide electrochemical potential window and so on. These features make ionic liquids become an alternative solution for electrodeposition of metals that cannot be electroplated in aqueous electrolytes. In this review, we classify investigated metals into three categories, which are light $(\mathrm{Li}, \mathrm{Mg})$, refractory $(\mathrm{Ti}, \mathrm{Ta})$ and noble $(\mathrm{Pd}, \mathrm{Pt}, \mathrm{Au})$ metals, rather than covering the exhaustive list of metals and try to update the recent development in this area. In electrodeposition of light metals, granular fine $\mathrm{Li}$ particles were successfully obtained while the passivation of electrodeposited $\mathrm{Mg}$ layers is an obstacle to reversible deposition-dissolution process of $\mathrm{Mg}$. In the case of refractory metals, the quality of Ta and Ti deposit particles was effectively improved with addition of LiF and pyrrole, respectively. In noble metal category, EMIM TFSA ionic liquid as an electrolyte for Au electrodeposition was proven to be effective and BMP TFSA ionic liquid developed a smooth Pd deposit. Pt nanoparticle production from ionic liquid droplet in aqueous solution can be cost-effective and display an excellent electrocatalytic activity.
\end{abstract}

Keywords : Ionic liquid, Electrodeposition, Light metal, Refractory metal, Noble metal, Morphology

\section{Introduction}

Ionic liquids are room-temperature molten salts in the liquid state. While ordinary liquids such as water are predominantly made of electrically neutral molecules, ionic liquids are largely made of ions and short-lived ion pairs. They are widely used in electrochemistry due to their unique properties such as non-volatility, inflammability, low toxicity, good ionic conductivity, wide electrochemical potential window and high thermal stability. These features make ionic liquids become an alternative solution for electrodeposition of metals that cannot be electroplated in aqueous electrolytes. The electrochemical window, which is the potential

*E-mail: kjkwon@sejong.ac.kr range of which the electrolyte is neither oxidized nor reduced, of ionic liquid should be wide enough to provide the reduction of metals with avoiding hydrogen embrittlement of the deposit layers or hydrogen evolution. Ionic liquids should also have a good electrochemical stability to prevent the reduction of their components during the electrodeposition of target metals. For ionic liquids to be practically adopted for electroplating industry, there are other key issues to be addressed. The viscosity of room temperature ionic liquids is much higher (accordingly, the ionic conductivity is lower) than that of aqueous electrolytes or high temperature molten salts due to a difference in ion size and also due to higher void volume. Besides, no definite relationship between the morphology of deposit and the experimental conditions has been 
established.

A few review papers dealing with the overview of metal electrodeposition in ionic liquids can be found elsewhere. ${ }^{1-3}$ In this review, we classify investigated metals into three categories, which are light $(\mathrm{Li}, \mathrm{Mg})$, refractory $(\mathrm{Ti}, \mathrm{Ta})$ and noble $(\mathrm{Pd}$, $\mathrm{Pt}, \mathrm{Au}$ ) metals, rather than covering the exhaustive list of metals and try to update the recent development in this area. In contrast to the previous review papers, we pay more attention to deposition morphology, which has not been intensively compared and analyzed.

\section{Light Metals}

\subsection{Lithium (Li)}

A main problem which is commonly found in $\mathrm{Li}$ rechargeable battery is the formation of dendritic $\mathrm{Li}$ metal deposits during charging, leading to short circuiting and poor cycling properties. Li dendrites are expected to grow because non-uniform films form when $\mathrm{Li}$ metal surface reacts with electrolyte solution. ${ }^{4}$ In recent years, studies about Li batteries are focused on attempts to avoid dendritic deposition by adding organic or inorganic reagents to electrolytes.

Sano et al. have studied the electrodeposition process of Li metal by using in situ morphological observation. ${ }^{5}$ They investigated the effect of organic reagent vinylene carbonate (VC) addition to two different ionic liquids, N-methyl-N-propylpiperidinium bis(trifluoromethanesulfonyl)amide (PP13 TFSA) and 1-ethyl-3-methylimidazolium bis(fluorosulfonyl)amide (EMIM FSA). Electrodeposition processes were done using $\mathrm{Ni}$ foil as working and counter electrode with Li TFSA as a source of Li. At the beginning of deposition process, potential rapidly drops and then slowly approaches $0 \mathrm{~V}$ as shown in Fig. 1(a). The initial decrease in potential is thought to be caused by the decomposition of electrolyte component. In the case of EMIM FSA as an electrolyte, there was no substantial difference between VC-free and VC-added samples. In situ observation by optical microscopy showed that both samples had a large distribution in particle size and some deposits grew fast to become larger than their neighbors. In contrast, for the case of PP13 TFSA, the authors observed a very small distribution in particle size for both VC-free and VC-added samples. Current density had a negligible effect on dendrite formation in the investigated range. The morphology of deposits in VC-free samples obtained at current densities of 50 and $150 \mu \mathrm{A} \mathrm{cm}^{-2}$ in EMIM FSA were almost the same. Ex situ observation by SEM showed that the deposit particles on both VC-free and VC-added samples in PP13 TFSA were very fine compared to other samples. The particle shape was dendritic for all samples in EMIM FSA ionic liquid and for the VC-free sample in PP13 TFSA, but the shape became granular for the VC-added sample in PP13 TFSA as shown in Fig. 1(b). It was concluded that PP13 TFSA has higher cathodic stability than that of EMIM FSA because of the coarser deposit

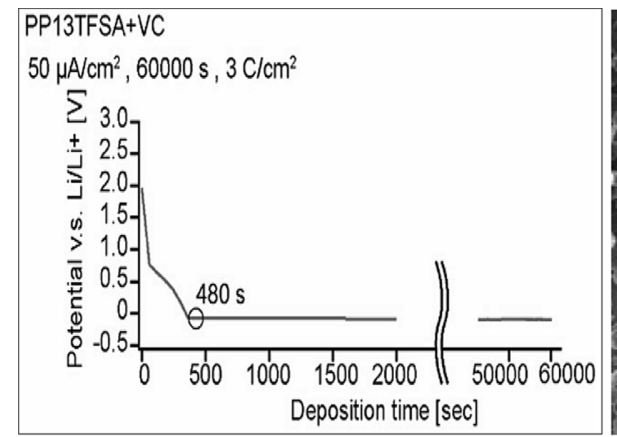

(a)

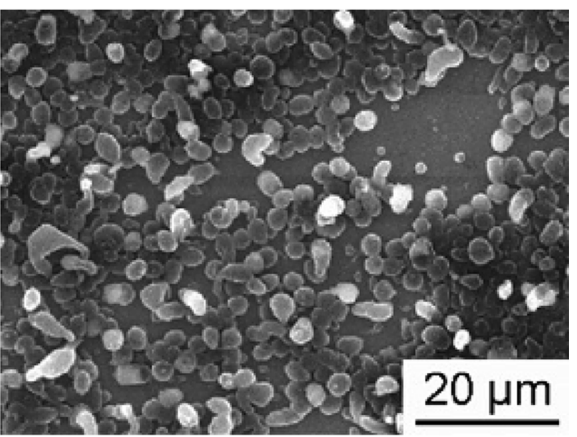

(b)

Fig. 1. (a) Change in potential during Li galvanostatic electrodeposition; (b) SEM image of Li electrodeposit formed galvanostatically on Ni substrate in PP13 TFSA solution with addition of VC at a current density of 50 $\mathrm{AA} / \mathrm{cm}^{2}$ and a charge of $3 \mathrm{C} / \mathrm{cm}^{2}$ for 60,000 seconds (Reprinted with permission from ref. [5] Copyright 2010 Elsevier B.V). 
grains of samples obtained in EMIM FSA than in PP13 TFSA. Regarding uniform and granular deposit particles for the case of VC-added sample in PP13 TFSA, Sano et al. clarified that the deposit film consisted of decomposed $\mathrm{VC}$ as a main component. A similar phenomenon was also reported by Ota et al., ${ }^{6}$ who stated that VC addition to electrolyte led to the formation of surface films consisting of poly-(VC) at elevated temperatures. The gel-like VC-derived polymeric surface film could prevent the deleterious reaction between deposited $\mathrm{Li}$ and the electrolyte, which resulted in enhanced cycling efficiency.

\subsection{Magnesium (Mg)}

The electrodeposition of $\mathrm{Mg}$, one of highly reactive metals, in ionic liquid is a complicated process and has complex problems. The selected electrolyte must be a polar aprotic solvent that should not react with $\mathrm{Mg}$ metal. Some previous studies clarified that electrode surface easily become passive. Passivation occurs probably due to the reaction of deposited $\mathrm{Mg}$ with several types of ionic liquid electrolyte or with trace water. Moreover, electrode surface could be covered by reduction products of dissolved organic or inorganic $\mathrm{Mg}$ salt species. When $\mathrm{Mg}$ is considered as an anode for rechargeable batteries, ionic liquid electrolyte should provide a wide electrochemical window for reversible deposition-dissolution reaction of $\mathrm{Mg}$.

$\mathrm{NuLi}$ et al. have reported for the first time that
$\mathrm{Mg}$ metal can be electrodeposited in 1-butyl-3methylimidazolium tetrafluoroborate $\left(\mathrm{BMIM} \mathrm{BF}_{4}\right.$ ) ionic liquid with $1 \mathrm{M} \mathrm{Mg}\left(\mathrm{CF}_{3} \mathrm{SO}_{3}\right)_{2}$ at room temperature. ${ }^{7}$ This electrolyte has $4.2 \mathrm{~V}$ and $3 \mathrm{~V}$ electrochemical windows on $\mathrm{Pt}$ disk and $\mathrm{Ag}$ plate electrodes, respectively. Four types of substrate (Pt, $\mathrm{Ag}, \mathrm{Ni}$ and stainless steel) were tried but only $\mathrm{Ag}$ substrate was feasible for electrodeposition of $\mathrm{Mg}$. Cyclic voltammogram of $\mathrm{Ag}$ electrodes in Fig. 2(a) shows anodic and cathodic peaks are located near $0 \mathrm{~V}$. The symmetrical shape and the sharp current peak indicate the process is reversible. The morphology of deposited $\mathrm{Mg}$ on $\mathrm{Ag}$ substrate was smooth and dense as shown in Fig. 2(b) while the morphology of deposits on Pt substrate was dendritic. These dendritic deposits were easily detached from substrate causing a loss of electrochemical active $\mathrm{Mg}$. A cyclic voltammetry test on $\mathrm{Ni}$ electrode exhibited a different behavior from $\mathrm{Pt}$ and $\mathrm{Ag}$ electrodes such as a strange shape of cathodic peak and a larger anodic charge than cathodic charge, which probably resulted from some side reactions on Ni electrode. Contrary to the three previous substrates, electrodeposition of $\mathrm{Mg}$ on stainless steel electrode required a larger overpotential than the other electrodes and a cross-over current was observed when the scan direction was reversed. It was concluded that the deposition and dissolution

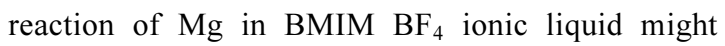
be related to some complicated interfacial processes that was not clear yet. The authors suggested that

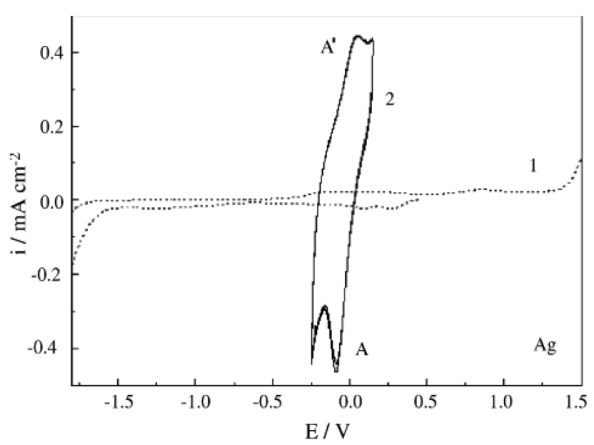

(a)

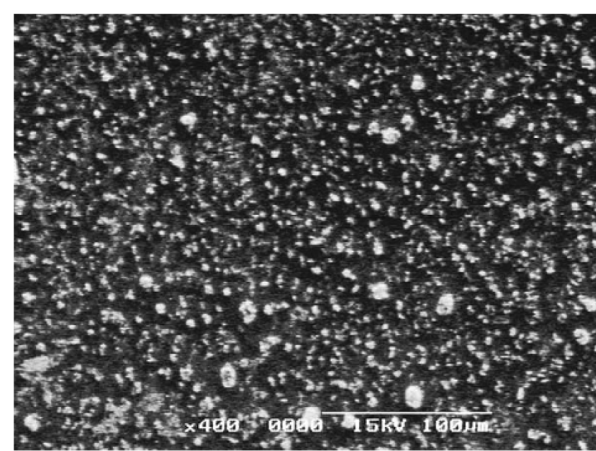

(b)

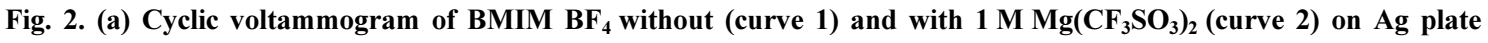
electrode at a scan rate $50 \mathrm{mV} / \mathrm{s}$; (b) $\mathrm{SEM}$ image of $\mathrm{Mg}$ film deposit formed potentiostatically on $\mathrm{Ag}$ plate in $\mathrm{BMIM} \mathrm{BF}_{4}$ solution containing $\mathrm{Mg}\left(\mathrm{CF}_{3} \mathrm{SO}_{3}\right)_{2}$ at a potential of $0.15 \mathrm{~V}$ vs. Pt QRE (Reprinted with permission from ref. [7] Copyright 2005 Elsevier B.V). 
BMIM $\mathrm{BF}_{4}$ ionic liquid might not be an ideal electrolyte for electrodeposition of $\mathrm{Mg}$ due to extremely slow diffusion coefficient in this ionic liquid.

Wang et $a l .{ }^{8}$ have investigated a possibility to mix two kinds of ionic liquids in order to design an ionic liquid system with a better performance and cycling property based on results from the aforementioned report. They used a mixture of BMIM $\mathrm{BF}_{4}$ and PP13 TFSA in a ratio of $2: 1,3: 1$ and $4: 1$, with $0.3 \mathrm{M} \mathrm{Mg}\left(\mathrm{CF}_{3} \mathrm{SO}_{3}\right)_{2}$ as a source of $\mathrm{Mg}$. Conductivity measurements indicated that a mixed solution has a higher conductivity than those of pure solutions and the conductivity increases as

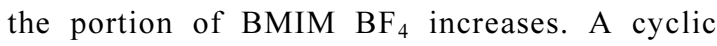
voltammetry test showed that the mixed ionic liquid has a wider electrochemical window than that of pure $\mathrm{BMIM} \mathrm{BF}_{4}$. SEM images at initial deposition on Ag substrate showed small crystallites (10-30 nm). At steady-state deposition, grains became bigger and deposits became more porous. An EDX analysis revealed that the deposits consisted of $\mathrm{Mg}$ and trace of $\mathrm{C}, \mathrm{O}$, and $\mathrm{F}$, which were expected from trapped ionic liquid in the porous structure of the $\mathrm{Mg}$ deposits. An XRD result showed that alloying of $\mathrm{Mg}$ and $\mathrm{Ag}$ occurred by diffusion of $\mathrm{Mg}$ into the bulk of $\mathrm{Ag}$ electrode. There observed a tradeoff such that increasing the portion of BMIM $\mathrm{BF}_{4}$ enhances the conductivity while increasing the portion of PP13 TFSA promotes the cathodic stability. The ratio of $4: 1$ was suggested to be the most suitable composition judging from an extremely low initial overpotential and a good cyclability up to 200 cycles.

In contrast with experiment results in ref [7] and [8], Amir et al. found that reversible $\mathrm{Mg}$ deposition-dissolution cannot be obtained from ethylmethylimidazolium-R, butylmethylimidazolium tetrafluoroborate and trihexyl(tetradecyl)phosphonium bis(trifluoromethylsulfonyl)imide $\left(\mathrm{P}_{66614}\right.$ TFSA) ionic liquids. ${ }^{9}$ A cyclic voltammetry measurement with $\mathrm{Pt}$ working electrode in $\mathrm{BMIM} \mathrm{BF}_{4}$ containing $0.5 \mathrm{M}$ $\mathrm{Mg}\left(\mathrm{CF}_{3} \mathrm{SO}_{3}\right)_{2}$ showing a lack of anodic peak suggested that deposited $\mathrm{Mg}$ would probably react with $\mathrm{BMIM}^{+}$. Voltammetric behavior of $\mathrm{Mg}$ electrode in the same ionic liquid indicated that $\mathrm{Mg}$ surface was passivated from the reaction of $\mathrm{Mg}$ with ionic liquid or trace of water. The authors concluded that the ionic liquid is not compatible with electrolytes in $\mathrm{Mg}$ batteries because most commonly used ionic liquids that have high cathodic stability are not suitable as a solvent for reversible $\mathrm{Mg}$ deposition-dissolution processes.

Since Shimamura et al. realized that reversible deposition-dissolution processes of $\mathrm{Mg}$ are practically difficult in ionic liquids containing simple $\mathrm{Mg}$ salts, they tried to obtain binary $\mathrm{Mg}-\mathrm{Li}$ composite by electrodeposition in N,N-diethyl$\mathrm{N}$-methyl-N-(2-methoxyethyl) ammonium bis (trifluoromethylsulfonyl)amide (DEME TFSA) containing $\mathrm{Mg}$ (TFSA) $)_{2}$ and Li TFSA. ${ }^{10}$ Cyclic voltammetry measurements revealed that addition of $\mathrm{Mg}$ salt can suppress the redox process of $\mathrm{Li}$ deposition and dissolution in ionic liquid. Potentiostatic electrodeposition was carried out on $\mathrm{Au}$ substrate at a potential $-3.5 \mathrm{~V}$ vs. Ag quasi reference electrode (QRE) in DEME TFSA containing $10 \mathrm{~mol} \% \mathrm{Li}$ TFSA and $10 \mathrm{~mol} \% \mathrm{Mg}$ $(\mathrm{TFSI})_{2}$ for 5 hours. An XRD pattern showed only $\mathrm{Mg}$ metal was contained in the deposited layers. Conversely, ICP-AES test results showed that both $\mathrm{Mg}$ and $\mathrm{Li}$ were chemically found in the deposits with current efficiencies of $28.8 \%$ and $24.6 \%$ respectively. Based on these contrast results by XRD and ICP-AES, the authors assumed the deposit layers consisted of amorphous Li containing metallic $\mathrm{Mg}$ and concluded that the simple cathodic reduction of $\mathrm{Mg}$ is difficult to proceed in DEME TFSA ionic liquid.

\section{Refractory Metals}

\subsection{Tantalum (Ta)}

Electrodeposition of $\mathrm{Ta}$ in ionic liquid electrolytes has been conducted in order to replace the use of high temperature molten salts of alkali metal halides which has low efficiency. TFSA is a popular choice of anion for $\mathrm{Ta}$ as ionic liquids including TFSA anion have high electrochemical stability and large electrochemical window. A major problem in electrodeposition of $\mathrm{Ta}$ is the tendency of deposited Ta to form non-stoichiometric subhalide species. Deposit layers usually show cracks and pores. Annealing process would be needed for the desired 
morphology of deposited layers. As it is well known that $\mathrm{Ta}$ has excellent corrosion resistance properties, it has a high tendency to form Ta oxide on deposited layers.

Abedin et al. reported the successful electrodeposition of $\mathrm{Ta}$ in room temperature ionic liquid for the first time. ${ }^{11}$ Cyclic voltammetry was done in 1-butyl-1-methylpyrrolidinium bis (trifluoromethanesulfonyl)amide (BMP TFSA) ionic liquid containing $0.5 \mathrm{M} \mathrm{TaF}_{5}$ on $\mathrm{Pt}$ working electrode. When the potential was set at $-2.3 \mathrm{~V}$ vs. Pt QRE for 1 hour, they observed black thick deposit was obtained with poor adherence to the substrate. Reduction and oxidation peaks grew with rising temperature due to kinetic reason. BMP TFSA was found to remain stable up to $300^{\circ} \mathrm{C}$ under inert gas conditions. Temperature also affected the quality of $\mathrm{Ta}$ deposit as a better adherence appeared at $200^{\circ} \mathrm{C}$. SEM and EDX analyses revealed that a deposit made at $200^{\circ} \mathrm{C}$ at a potential of $-1.3 \mathrm{~V}$ vs. Pt QRE for 1 hour was granule particles and contained mainly Ta contaminated with $\mathrm{C}, \mathrm{O}, \mathrm{F}$ and $\mathrm{S}$. In contrast, an XRD analysis showed no evidence for crystalline $\mathrm{Ta}$ in the deposit. After annealing process at $800^{\circ} \mathrm{C}$ under vacuum condition for 5 hours, XRD reinvestigation confirmed that the deposit contained crystalline $\mathrm{Ta}$ and $\mathrm{Ta}_{2} \mathrm{O}_{5}$. The EDX analysis of annealed sample showed that micro-scale non-stoichiometric Ta subfluoride layers with some trapped ionic liquids grew on a thin crystalline Ta layers $(200-300 \mathrm{~nm})$. The authors also tried to electrodeposit $\mathrm{Ta}$ on $\mathrm{Au}$ (111) substrate in the same electrolyte. Contrary to the Pt substrate case, the reduction process on Au substrate occurs in two steps. The first step was presumed to be the reduction of $\mathrm{Ta}(\mathrm{V})$ to $\mathrm{Ta}$ (III) and the second step was the reduction of Ta (III) to elemental Ta. Deposited Ta on Au substrate also showed enhanced adherence and mechanical quality at $200^{\circ} \mathrm{C}$ compared to room temperature as similarly observed on $\mathrm{Pt}$ substrate. A SEM analysis of deposited layers made at $200^{\circ} \mathrm{C}$ at a potential of $-1.2 \mathrm{~V}$ vs. Pt QRE for 1 hour showed thick and dense deposits containing a few cracks. An addition of $\mathrm{LiF}$ to the electrolyte was also proved to be an effective way to improve mechanical quality and adherence of electrodeposited Ta. With addition of $\mathrm{LiF}$, the reduction process of $\mathrm{Ta}(\mathrm{V})$ to elemental Ta occurred in three steps as observed in cyclic voltammogram (Fig. 3(a)) where three cathodic peaks appear and deposited Ta showed a smooth, coherent and dense layer as shown in Fig. 3(b). The authors attributed these results to ionic polarizability of $\mathrm{Li}^{+}$which can weaken Ta-F bonds and facilitate Ta deposition.

A further study on electrodeposition of Ta was done with a focus on corrosion behavior of electroplated alloy. ${ }^{12}$ Based on the results from the previous study, ${ }^{11}$ electrodeposition of Ta in BMP TFSA ionic liquid containing $0.25 \mathrm{M} \mathrm{TaF}_{5}$ and 0.25 M LiF was carried out at $200^{\circ} \mathrm{C}$ on NiTi alloy. A non-stoichiometric layer of Ta subhalide on top of

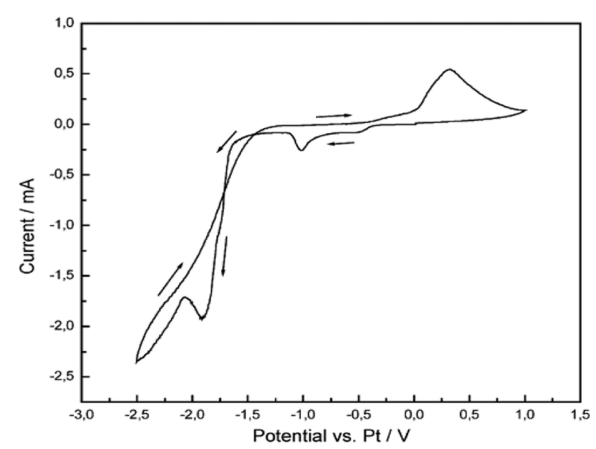

(a)

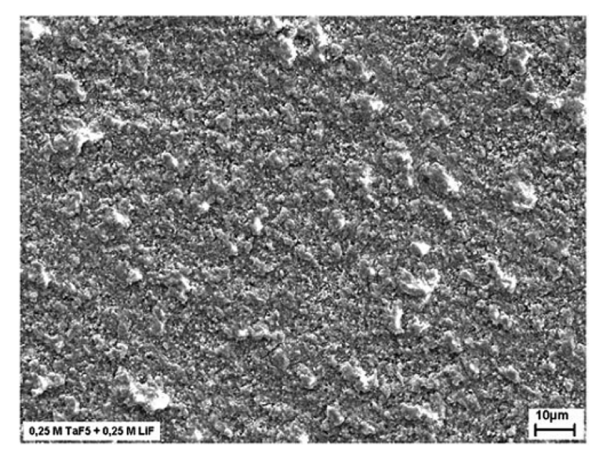

(b)

Fig. 3. (a) Cyclic voltammogram of BMP TFSA containing $0.25 \mathrm{M} \mathrm{TaF}_{5}$ and $0.25 \mathrm{M} \mathrm{LiF}$ on Pt electrode at $200^{\circ} \mathrm{C}$; (b) SEM image of Ta electrodeposit formed potentiostatically on Pt substrate in BMP TFSA solution containing $0.25 \mathrm{M}^{\mathrm{TaF}} \mathrm{F}_{5}$ and $0.25 \mathrm{M} \mathrm{LiF}$ at a potential of $1.8 \mathrm{~V}$ vs. Pt QRE for 1 hour at $200^{\circ} \mathrm{C}$ (Reprinted with permission from ref. [11] Copyright 2005 The Owner Societies). 
the elemental Ta was similarly observed and the Ta subhalide layers became thicker with increasing current density. Corrosion measurements of coated and uncoated NiTi alloy revealed some significant results as follows: (i) open circuit potential of the coated sample was about $150 \mathrm{mV}$ higher than that of uncoated one; (ii) polarization curve showed $300 \mathrm{mV}$ of a passive region of uncoated sample while coated sample showed a wider passive region up to $600 \mathrm{mV}$; (iii) corrosion potential of the coated sample was higher than that of the uncoated one. These results validate the argument that deposition of $\mathrm{Ta}$ as thin as $500 \mathrm{~nm}$ thick can increase the corrosion resistance of NiTi alloy.

Borisenko et al. investigated the electrodeposition of $\mathrm{Ta}$ at room temperature on flame-annealed $\mathrm{Au}$ and on polycrystalline Au substrates in BMP TFSA containing $\mathrm{TaF}_{5}$ as a source of $\mathrm{Ta}^{13} \mathrm{~A}$ cyclic voltammetry test showed a wide electrochemical window of the ionic liquid up to $6 \mathrm{~V}$. The reduction process of $\mathrm{TaF}_{5}$ to elemental $\mathrm{Ta}$ in this electrolyte takes four subsequent steps. If a deposition rate is very fast with a very slow diffusion rate of $\mathrm{F}^{-}$, the reduction process would involve $\mathrm{F}^{-}$which results in $\mathrm{TaF}_{\mathrm{x}}$ formation. Partial reduction of $\mathrm{TaF}_{\mathrm{x}}$ to elemental $\mathrm{Ta}$ will lead to a porous structure and cracks on deposit surface. Increasing temperature and stirring solution can be used to avoid formation of subhalide species and to obtain thicker deposited layers. EDX and XRD analyses indicated that deposited layers mainly consisted of elemental Ta with a minority of Ta oxides. In contrast with high temperature molten salts, Ta can be electrodeposited in thin layers under relatively simple experimental conditions using the ionic liquid.

In order to study the effect of cation, Ispas et al. have studied the electrodeposition process of $\mathrm{Ta}$ using three different ionic liquids: BMP TFSA, 1ethyl-3-methylimidazolium bis(trifluoromethylsulfonyl)amide (EMIM TFSA) and 1-methyl-3-propylimidazolium bis(trifluoromethylsulfonyl)amide (PMIM TFSA). ${ }^{14}$ It was found by EQCM measurements that no elemental Ta could be obtained from EMIM TFSA containing $0.5 \mathrm{M} \mathrm{TaF}_{5}$ neither at room temperature nor at temperatures higher than $100^{\circ} \mathrm{C}$. The problem of subhalide formation also occurred in this study. By calculating the apparent molar mass, they found that increasing temperature to $120^{\circ} \mathrm{C}$ could decrease the tendency of subhalide formation in the following order: EMIM TFSA $>$ PMIM TFSA $\geq$ BMP TFSA. Similarly to the experiment results in ref. [13], Ta reduction process in this report occurred through several intermediate steps with low rate constants. A square-wave voltammetry showed that rate constants decreased as the oxidation state of Ta approached zero. Desirable morphology of deposits on $\mathrm{Au}$ substrate by potentiostatic and galvanostatic electrodeposition experiments was not obtained at room temperature with the range of potential from $-1.25 \mathrm{~V}$ to $-2.3 \mathrm{~V}$ vs. Pt QRE and the current densities of $-0.1 \mathrm{~mA} / \mathrm{cm}^{2}$ and $-0.05 \mathrm{~mA} / \mathrm{cm}^{2}$. Galvanostatic deposition at room temperature usually ended up with cracked layers, as in potentiostatic deposition, with more roundish grains. Increasing temperature would reduce cracks and form more compact layers. XPS data displayed that elemental Ta can only be obtained in a narrow deposition range owing to high affinity of elemental $\mathrm{Ta}$ to form compounds with $\mathrm{F}$ and $\mathrm{O}$.

\subsection{Titanium (Ti)}

Electrodeposition of $\mathrm{Ti}$ is facing several problems to become commercialized such as requirement of large nuclei, very reactive deposit, complex redox process and formation of intermediate species. In recent years, attempts to electrodeposit $\mathrm{Ti}$ at room temperature become an interesting research object mainly in determining proper types of ionic liquid as an electrolyte.

Some studies have been done in ionic liquids with TFSA anion thanks to their high electrochemical stability. Mukhopadhyay et al. first investigated electrodeposition of elemental $\mathrm{Ti}$ at room temperature using in situ electrochemical scanning tunneling microscopy (STM). ${ }^{15} \mathrm{Au}$ (111) was used as a substrate with $0.24 \mathrm{M} \mathrm{TiCl}_{4}$ as a source of $\mathrm{Ti}$ in BMIM TFSA. A current transient curve showing no sharp passivation transient indicated no substantial concentration of $\mathrm{TiCl}_{3}$ precipitates during $\mathrm{TiCl}_{4}$ reduction. STM observation showed that $2 \mathrm{D}$ islands were formed at a potential $-0.5 \mathrm{~V}$ vs. Pt. In the underpotential deposition region below $-1.4 \mathrm{~V}$ vs. $\mathrm{Pt}$, those islands completely covered the Au substrate 


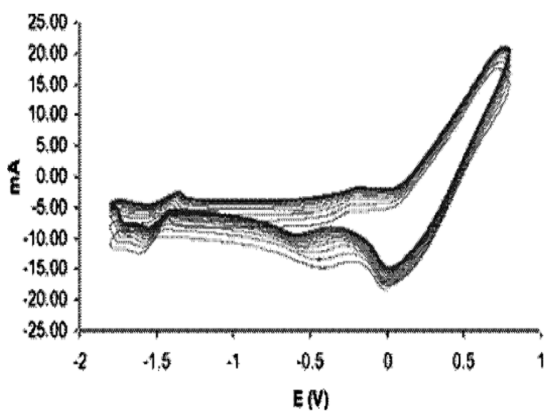

(a)

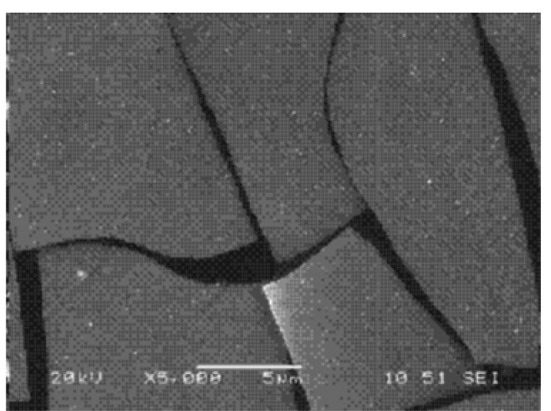

(b)

Fig. 4. (a) Cyclic voltammogram of EMIM TFSA containing $0.59 \mathrm{M} \mathrm{TiCl}_{4}$ and $0.06 \mathrm{M}_{\text {pyrrole on }} \mathrm{GC}$ electrode at a scan rate $50 \mathrm{mV} / \mathrm{s}$; (b) SEM image of Ti electrodeposit formed potentiostatically on GC electrode in EMIM TFSA solution containing $0.59 \mathrm{M} \mathrm{TiCl}_{4}$ and $0.06 \mathrm{M}$ pyrrole at a potential of $-1.8 \mathrm{~V}$ vs. $\mathrm{Ag} / \mathrm{Ag}^{+}$for 3 hours (Reprinted with permission from ref. [17] Copyright 2007 Elsevier B.V).

with two atomic layers of Ti. During overpotential deposition process at a potential $-1.8 \mathrm{~V}$ vs. $\mathrm{Pt}$ QRE, they observed the growth of $3 \mathrm{D}$ clusters forming bulk of Ti. After the dissolution of deposited Ti layers, a large number of monatomic depth holes on $\mathrm{Au}$ surface were observed, which is indicative of Au-Ti surface alloying.

Endres et al. tried to study further about electrodeposition of $\mathrm{Ti}$ from its halides. ${ }^{16} \mathrm{In}$ contrast with the results in ref. [15], they did not obtain any evidence that elemental $\mathrm{Ti}$ could be electrodeposited from its halides in ionic liquids. No elemental $\mathrm{Ti}$ was electrodeposited neither from EMIM TFSA containing $0.25 \mathrm{M} \mathrm{TiCl}_{4}$ at $100^{\circ} \mathrm{C}$ nor from the ionic liquid using other $\mathrm{Ti}$ sources such as $\mathrm{TiF}_{4}$ and $\mathrm{TiI}_{4}$ even at $200^{\circ} \mathrm{C}$. Another attempt in using Ti-isopropanolate as a $\mathrm{Ti}$ source and $\mathrm{P}_{66614}$ TFSA ionic liquid also ended up with observing cation decomposition products instead of elemental Ti. When BMP TFSA was used in electrolyte, some islands on $\mathrm{Au}$ (111) surface, which could be attributed to the formation of metal $\mathrm{Ti}$ and/or subhalide $\mathrm{TiCl}_{\mathrm{x}}$, were found at a potential of $-2.2 \mathrm{~V}$ vs. Pt. A stepwise shift of potential in anodic direction resulted in small tiny pits on Au surface, indicative of the formation of ultrathin layer of $\mathrm{Au}$ Ti alloy. The authors also reported that $\mathrm{TiCl}_{4}$ can form complexes with the TFSA anion along with the formation of $\mathrm{TiCl}_{\mathrm{x}}$. This complex formation could shift the electrode potential for $\mathrm{Ti}$ deposition below the cathodic decomposition limit of the ionic liquid. Extended electrodeposition experiments suggested that limited solubility of Ti halides may be the reason why it was extremely difficult to electrodeposit Ti from its halides.

Based on the past studies about electrochemical separation of $\mathrm{Cu}$ and $\mathrm{Au}$ using conducting polymers, Ding et al. tried to implement the same technique for $\mathrm{Ti}$, which needs large nuclei to be electrodeposited. ${ }^{17}$ They used glassy carbon (GC) electrode coated with polypyrrole (PPy) in EMIM TFSA solution and found that the conductivity of PPy decreased at low potentials resulting in a very thin film. Another attempt to use monomer pyrrole with concentration $0.06 \mathrm{M}$ was tried in order to study the possibility of pyrrole to create conducting polymer nucleation site in situ. Cyclic voltammogram as shown in Fig. 4(a) indicates the oxidation of pyrrole and the redox reaction of $\mathrm{TiCl}_{4}$ as well as polypyrrole deposition. Under the same condition as the PPy case $(0.18 \mathrm{~V}$ for 3 hours $)$, a very smooth surface containing very rich $\mathrm{Ti}$ was obtained as shown in Fig. 4(b). The authors also found that $\mathrm{TiCl}_{2}$ and $\mathrm{TiCl}_{3}$ have a very limited solubility in EMIM TFSA by investigating the redox chemistry of Ti (II) and Ti (III) chloride. As a result, low solubility of reduced $\mathrm{Ti}$ species along with polymerization of pyrrole in situ enabled the stable deposition of elemental $\mathrm{Ti}$ at room temperature from $\mathrm{TiCl}_{4}$ in EMIM TFSA solution.

An alternative way in electrodeposition of $\mathrm{Ti}$ using ionic liquid was introduced by Zhang et al. ${ }^{18}$ Instead of adding $\mathrm{Ti}$ halides as a source of $\mathrm{Ti}$, they used $\mathrm{Ti}$ oxide by oxidizing pure $\mathrm{Ti}$ foil. A cyclic 
voltammetry was conducted in $\mathrm{AlCl}_{3}$-1-butyl-3methylimidizolium chloride $\left(\mathrm{AlCl}_{3}\right.$-BMIM $\left.\mathrm{Cl}\right)$ at $343 \mathrm{~K}$ using $\mathrm{Pt}$ wire as a counter electrode and $\mathrm{Ag}$ wire as a reference electrode. A reduction process of $\mathrm{TiO}_{2}$ in $\mathrm{AlCl}_{3}$-BMIM $\mathrm{Cl}$ occurred at interface between $\mathrm{TiO}_{2}$ film and bulk ionic liquid. They summarized the reduction process as follows:

Cathode: $\quad \mathrm{TiO}_{2}+4 \mathrm{e} \rightarrow \mathrm{Ti}+2 \mathrm{O}_{2}^{-}$

Anode: $2 \mathrm{O}_{2}^{-} \rightarrow \mathrm{O}_{2} \uparrow+4 \mathrm{e}$

The authors also tried to electrodeposit $\mathrm{Ti}$ from $\mathrm{TiO}_{2}$ pellet which was synthesized by sol-gel method. Electrolysis reaction rate was very slow and only about $12 \mathrm{wt} \%$ of $\mathrm{TiO}_{2}$ was reduced to metallic Ti after 48 hours at $373 \mathrm{~K}$ with higher overpotential applied than that of oxidized $\mathrm{Ti}$ foil. It was concluded that Lewis basic ionic liquid $\mathrm{AlCl}_{3}$-BMIM $\mathrm{Cl}$ could be used for electrodeposition of elemental Ti from $\mathrm{TiO}_{2}$ at low temperature. Nevertheless, this ionic liquid is corrosive and unstable against air and moisture so that it needs special treatment during handling.

\section{Noble Metals}

\subsection{Gold (Au)}

$\mathrm{Au}$ electrode as an inert material is widely used as a substrate for electrodeposition of metals, semiconductors or conducting polymers in room temperature ionic liquids. However, only few studies have been done regarding electrodeposition of $\mathrm{Au}$ in ionic liquids. A common problem in electrodeposition of $\mathrm{Au}$ is the presence of cyanide $\left(\mathrm{CN}^{-}\right)$species in electrodeposition bath as decomposition product which could be adsorbed on electrodeposited Au film.

Due to a large electrochemical window $(4.6 \mathrm{~V}$ on GC electrode), a relatively low dynamic viscosity $(40.1 \mathrm{mPa} s$ at $293 \mathrm{~K})$ and a relatively high conductivity $\left(8.8 \mathrm{mS} \mathrm{cm}^{-1}\right.$ at $\left.293 \mathrm{~K}\right)$, EMIM TFSA ionic liquid was chosen by Bozzini et al. ${ }^{19}$ as an electrolyte for the electrodeposition of $\mathrm{Au}$ from $\mathrm{K}\left[\mathrm{Au}(\mathrm{CN})_{2}\right]$. They concluded that an optimal potential for potentiostatic electrodeposition of $\mathrm{Au}$ is in the range from $-1.3 \mathrm{~V}$ to $-1.6 \mathrm{~V}$ vs. $\mathrm{Au}$ QRE. SEM micrographs showed that the morphology of deposit films was changed from a discontinuous layer of nanometric spheroidal particles to a continuous layer composed of micrometric acicular grains after 180 minutes of electrodeposition process. Based on XPS analysis, they found that deposit films consisted of pure $\mathrm{Au}$ without contamination of $\mathrm{CN}^{-}$and organic additives. This is clearly an advantage of EMIM TFSA ionic liquid because $\mathrm{Au}$ films produced in aqueous solution are usually contaminated by $\mathrm{CN}^{-}$ and organic additives. ${ }^{20,21}$

Bozzini et al. also studied the electrodeposition of $\mathrm{Au}$ in hydrophobic BMP TFSA bath containing $\mathrm{K}\left[\mathrm{Au}(\mathrm{CN})_{2}\right] .{ }^{22}$ They used flame-annealed polycrystalline $\mathrm{Au}$ as a working electrode and $\mathrm{Au}$ wire as a quasi-reference as well as counter

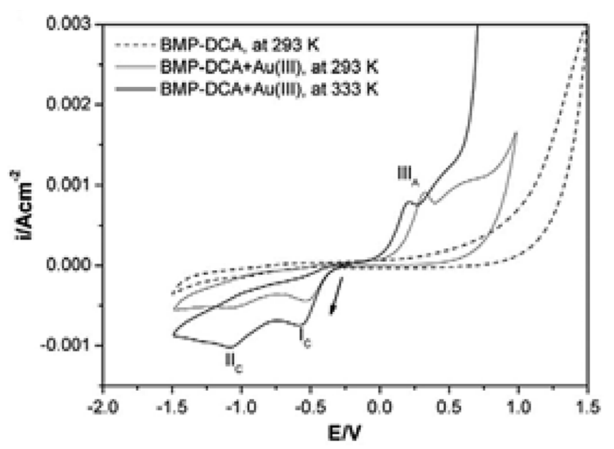

(a)

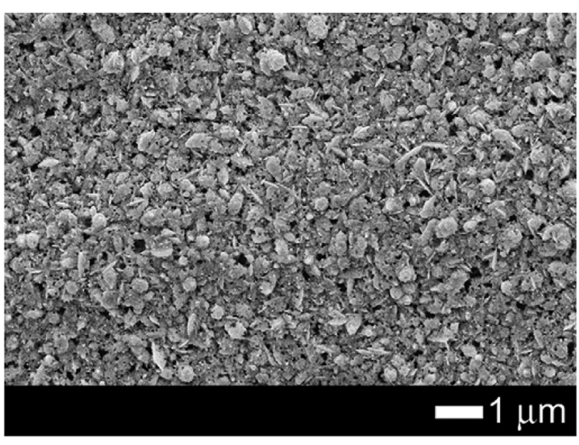

(b)

Fig. 5. (a) Cyclic voltammogram of BMP DCA at $293 \mathrm{~K}$ and $\mathrm{BMP}$ DCA $+0.020 \mathrm{M} \mathrm{HAuCl}_{4} .3 \mathrm{H}_{2} \mathrm{O}$ solution on $\mathrm{Ni}$ substrate at 293 and $333 \mathrm{~K}$; (b) SEM image of Au electrodeposit formed potentiostatically on Ni substrate in BMP DCA solution containing $\mathrm{HAuCl}_{4} \cdot 3 \mathrm{H}_{2} \mathrm{O}$ at a potential of $-1 \mathrm{~V}$ vs. Au QRE for 4500 seconds (Reprinted with permission from ref. [23] Copyright 2011 Elsevier B.V). 
electrode. Cyclic voltammetry showed that electrochemical window of this ionic liquid is wide enough, about 5 V. From in situ 2D visible-infrared sum frequency generation study, they found that the pyrrolidinium ring of $\mathrm{BMP}^{+}$is coadsorbed with $\mathrm{CN}^{-}$-containing species and tends to reorient from a vertical equatorial adsorption conformation under cathodic conditions to an axial conformation-with the ring parallel to the surface-in the anodic range.

De Sá et al. revealed that $\mathrm{Au}$ thin films can be electrodeposited in normal atmospheric conditions from $\mathrm{HAuCl}_{4} .3 \mathrm{H}_{2} \mathrm{O}$ in 1-butyl-1-methylpyrrolidinium dicyanamide (BMP DCA). ${ }^{23}$ They chose this ionic liquid due to its low viscosity and strong capability to form complex species based on the Lewis basic character of the DCA anion. Cyclic voltammetry using Ni (Fig. 5(a)) and GC electrodes showed that the reduction of $\mathrm{Au}^{3+}$ is a two-step process. First, $\mathrm{Au}^{3+}$ was reduced to $\mathrm{Au}^{+}$, followed by the reduction of $\mathrm{Au}^{+}$to $\mathrm{Au}^{0}$. Potentiostatic electrodeposition on $\mathrm{Ni}$ substrate at a potential $-1 \mathrm{~V}$ vs. Au QRE for 1500 seconds developed golden-brown thin film deposits. For deposition temperatures of $293 \mathrm{~K}$ and $333 \mathrm{~K}$, the film morphology was discontinuous with poor adherence to the substrate. Increasing temperature to $353 \mathrm{~K}$ resulted in a thin continuous layer of nanoparticles covered by large dendritic particles. Increasing deposition time will decrease the density of dendrites although very small pores still remain on $\mathrm{Au}$ thin films even after 4500 seconds deposition time as shown in Fig. 5(b). The authors suggested a hypothesis that BMP cation acts as a grain refiner because it forms a large number of solvation layers on a liquid/metal interface hindering the growth of the deposit particles. Electrodeposited Au thin films in BMP DCA ionic liquid were much finer than those deposited from aqueous solutions.

\subsection{Palladium (Pd)}

Pd metal is usually obtained by electrodeposition from aqueous bath. This conventional method has a problem of low hydrogen overpotential causing hydrogen dissolution in $\mathrm{Pd}$ metal and the resulting embrittlement of deposited layers. In order to enhance the quality of Pd deposit and to avoid hydrogen evolution, a new aprotic electrolyte is needed. Room temperature ionic liquids which have wide electrochemical window are expected to be an alternative media for electrodeposition of Pd.

Tai et al. investigated the electrodeposition of Pd$\mathrm{Ag}$ solid solution alloy, which is used for electrical materials and catalytic applications, in Lewis basic 1-ethyl-3-methylimidazolium chloride-tetrafluoroborate (EMIM Cl-BF 4 ) ionic liquid. ${ }^{24}$ Potentiostatic deposition of $\mathrm{Pd}-\mathrm{Ag}$ alloy was done on $\mathrm{Ni}$ substrate in a range of applied potential from 0.53 to $0.73 \mathrm{~V}$ vs. $\mathrm{Al} \mathrm{QRE}$ at $35^{\circ} \mathrm{C}$. The diffusion coefficient of $\mathrm{Pd}^{2+}$ is less than that of $\mathrm{Ag}^{+}$leading to a lower $\mathrm{Pd}$ content in the deposits than that in the plating bath. Increasing $\mathrm{Pd}$ content in plating bath would generate more compact deposits with

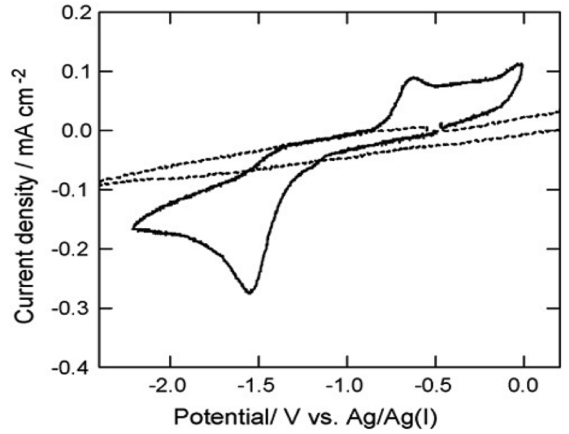

(a)

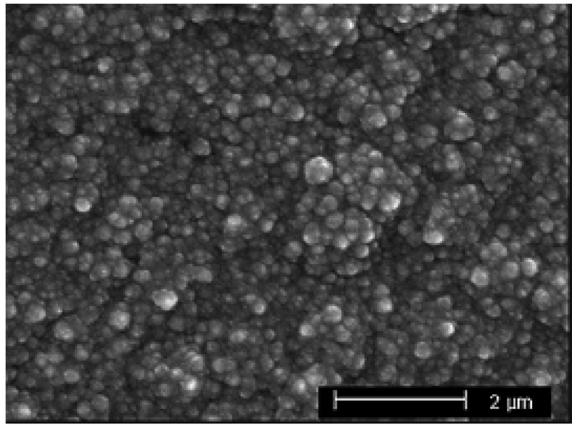

(b)

Fig. 6. (a) Cyclic voltammogram of BMP TFSA with (-) and without (---) $0.01 \mathrm{M} \mathrm{PdBr}_{4}{ }^{2}$ on $\mathrm{Pt}$ electrode at $25^{\circ} \mathrm{C}$ at a scan rate $50 \mathrm{mV} / \mathrm{s}$; (b) SEM image of Pd electrodeposit formed galvanostatically on Ni substrate in BMP TFSA solution containing $\mathrm{PdBr}_{4}{ }^{2}$ at a current density of $0.01 \mathrm{~mA} / \mathrm{cm}^{2}$ (Reprinted with permission from ref. [26] Copyright 2007 Elsevier Ltd). 
nodular grains and fine crystal sizes. Moreover, increasing temperature would reduce the overpotential required for the reduction of $\mathrm{Pd}$, which leads to higher Pd content in the deposited alloy.

It is known that BMP TFSA is immiscible with water with a very low melting point $\left(18^{\circ} \mathrm{C}\right)$ and high electrochemical stability. ${ }^{25}$ Triggered by these advantages, Bando et al. investigated BMP TFSA as an electrolyte for electrodeposition of Pd from some Pd halide complexes at room temperature. ${ }^{26}$ Fig. 6(a) shows the cyclic voltammogram of $\mathrm{Pt}$ electrode in BMP TFSA containing $0.01 \mathrm{M} \mathrm{PdBr}_{4}{ }^{2-}$. The cathodic and anodic peaks are observed at $-1.6 \mathrm{~V}$ and $-0.4 \mathrm{~V}$, respectively. Potentiostatic cathodic reduction on $\mathrm{Ni}$ electrode at $-1.7 \mathrm{~V}$ vs. $\mathrm{Ag} / \mathrm{Ag}^{+}$developed planar and granular deposits which were identified as metallic Pd by XRD and XPS analyses. Therefore, it was confirmed that the cathodic peak on voltammogram was due to the reduction reaction of $\mathrm{Pd}^{2+}$ to $\mathrm{Pd}^{0}$ and the anodic peak could be assigned as the dissolution of electrodeposited $\mathrm{Pd}$. They found that the morphology of deposits obtained by galvanostatic electrodeposition depended on the current densities. That is, a higher current density results in powdery deposits while a lower current density results in smooth deposits as shown in Fig. 6(b). The authors also examined $\mathrm{PdCl}_{4}{ }^{2-}$ which is commonly used as a source of $\mathrm{Pd}$ in industrial $\mathrm{Pd}$ electroplating. From cyclic voltammetry, it was shown that the electrodeposition of $\mathrm{Pd}$ from $\mathrm{PdCl}_{4}{ }^{2-}$ in BMP TFSA was also possible with more negative reduction potentials due to larger donor number of $\mathrm{Cl}^{-}$than that of $\mathrm{Br}^{-}$.

\subsection{Platinum (Pt)}

Much interest has been paid to the production of Pt nanoparticles in recent years due to their important role as a catalyst in many chemical reactions. Electrodeposition in ionic liquid seems to be an efficient method to produce Pt nanoparticles with simple instrumentation and low cost. Studies usually focus on attempts to electrodeposit $\mathrm{Pt}$ nanoparticles with minimum cost and high electrocatalytic properties.

$\mathrm{He}$ et al. investigated electrodeposition of $\mathrm{Pt}$ nanoparticles from room temperature ionic liquids, i.e. BMIM $\mathrm{BF}_{4}$ and 1-butyl-3-methylimidazolium hexafluorophosphate $\left(\mathrm{BMIM} \mathrm{PF}_{6}\right)$ for the first time. $^{27}$ These two ionic liquids have significant different properties. The viscosity of hydrophobic BMIM $\mathrm{PF}_{6}$ is 2-3 times larger than that of hydrophilic $\mathrm{BMIM} \mathrm{BF}_{4}$. Cyclic voltammetry of $\mathrm{GC}$ electrode showed that both ionic liquids have electrochemical window more than $4 \mathrm{~V}$. Potentiostatic reduction was carried out in both ionic liquids with $\mathrm{H}_{2} \mathrm{PtCl}_{6}$ as a source of $\mathrm{Pt}$ at a potential $-1.5 \mathrm{~V}$ vs. $\mathrm{Ag} / \mathrm{AgCl}$. For comparison, electrodeposition of $\mathrm{Pt}$ was also done in $\mathrm{HClO}_{4}$ aqueous solution at potential $-0.1 \mathrm{~V}$ vs. $\mathrm{Ag} / \mathrm{AgCl}$.

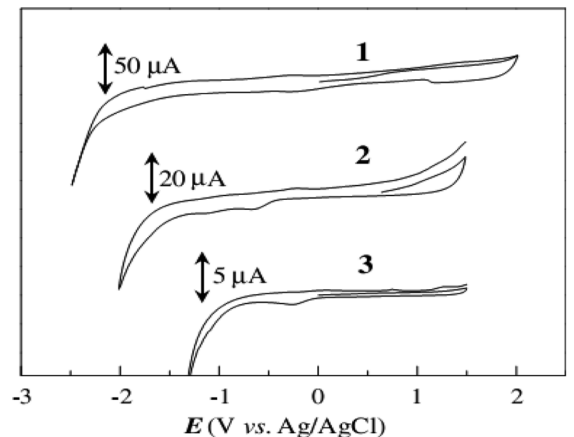

(a)

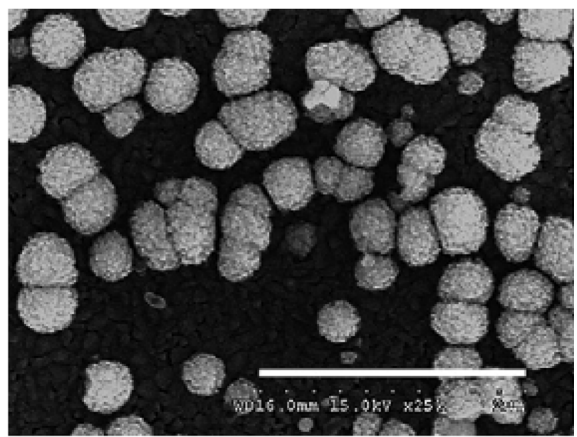

(b)

Fig. 7. (a) Cyclic voltammogram of $\mathrm{BMIM} \mathrm{PF}_{6}$ droplet containing $\mathrm{H}_{2} \mathrm{PtCl}_{6}$ supported onto GC electrode in $0.1 \mathrm{M} \mathrm{KPF}_{6}$ solution (curve 2) and at bare GC electrode in the pure ionic liquid solvent (curve 1) and in $0.1 \mathrm{M} \mathrm{KPF}_{6}$ solution (curve 3) at a scan rate $100 \mathrm{mV} / \mathrm{s}$; (b) SEM images of Pt nanoparticles electrodeposited on ITO electrodes from BMIM PF $\mathrm{Br}_{6}$ droplet containing $\mathrm{H}_{2} \mathrm{PtCl}_{6}$ supported onto ITO in $0.1 \mathrm{M} \mathrm{KPF}_{6}$ solution at a potential of $-1.5 \mathrm{~V}$ vs. Ag/AgCl for 500 seconds (Reprinted with permission from ref. [28] Copyright 2007 Elsevier B.V). 
Table 1. Summary of electrodeposited metal characteristics and experiment conditions.

\begin{tabular}{|c|c|c|c|c|c|c|c|}
\hline Category & Element & Salt & Ionic Liquid & Substrate & Temp & Deposit & Ref \\
\hline \multirow{6}{*}{$\begin{array}{l}\text { Light } \\
\text { Metals }\end{array}$} & & & EMIM FSA & & & $\begin{array}{l}\text { With and without VC: } \\
\text { - Large distribution in particle size. } \\
\text { - Dendritic and coarse particles. }\end{array}$ & \\
\hline & $\mathrm{Li}$ & Li TFSA & PP13 TFSA & $\mathrm{Ni}$ & RT & $\begin{array}{l}\text { With VC: } \\
\text { - Very small distribution in } \\
\text { particle size. } \\
\text { - Granular and fine particles. } \\
\text { Without VC: } \\
\text { - Very small distribution in } \\
\text { particle size. } \\
\text { - Dendritic and fine particles. }\end{array}$ & [5] \\
\hline & \multirow{4}{*}{$\mathrm{Mg}$} & $\mathrm{Mg}\left(\mathrm{CF}_{3} \mathrm{SO}_{3}\right)_{2}$ & $\mathrm{BMIM} \mathrm{BF}_{4}$ & $\begin{array}{l}\text { Pt, Ag, Ni, } \\
\text { S.S. }\end{array}$ & RT & $\begin{array}{l}\text { - On } \mathrm{Ag} \text { : smooth and dense } \\
\text { - On Pt : dendritic }\end{array}$ & [7] \\
\hline & & $\mathrm{Mg}\left(\mathrm{CF}_{3} \mathrm{SO}_{3}\right)_{2}$ & $\begin{array}{l}\text { mixture of BMIM } \\
\mathrm{BF}_{4} \text { and PP13 TFSA }\end{array}$ & $\mathrm{Ag}$ & RT & Porous structure & [8] \\
\hline & & $\begin{array}{l}\mathrm{MgCl}_{2} \\
\mathrm{Mg}\left(\mathrm{CF}_{3} \mathrm{SO}_{3}\right)_{2} \\
\mathrm{Mg}\left(\mathrm{ClO}_{4}\right)_{2} \\
\mathrm{Mg}\left(\mathrm{CH}_{3}\left(\mathrm{CH}_{2}\right)_{3}\right)_{2}\end{array}$ & $\begin{array}{l}\text { ethylmethylimidazo } \\
\text { ium-R, BMIM BF } \\
\mathrm{P}_{66614} \text { TFSA }\end{array}$ & $\mathrm{Pt}$ & RT & Passivated & [9] \\
\hline & & $\begin{array}{l}\text { Li TFSA + Mg } \\
(\text { TFSA) })_{2}\end{array}$ & DEME TFSA & $\mathrm{Au}$ & RT & $\begin{array}{l}\text { Amorphous Li containing } \\
\text { metallic } \mathrm{Mg}\end{array}$ & [10] \\
\hline \multirow{14}{*}{$\begin{array}{l}\text { Refrac-tory } \\
\text { Metals }\end{array}$} & \multirow{8}{*}{$\mathrm{Ta}$} & \multirow[t]{2}{*}{$\mathrm{TaF}_{5}$} & \multirow[t]{3}{*}{ BMP TFSA } & $\mathrm{Pt}$ & $200^{\circ} \mathrm{C}$ & $\begin{array}{l}\text { - Granule particles contained } \\
\text { crystalline Ta and } \mathrm{Ta}_{2} \mathrm{O}_{5} \text {. } \\
\text { - Ta subhalide on top of the } \\
\text { elemental Ta. }\end{array}$ & \multirow[t]{3}{*}{ [11] } \\
\hline & & & & $\mathrm{Au}$ & & $\begin{array}{l}\text { Thick and dense deposit } \\
\text { contained a few cracks }\end{array}$ & \\
\hline & & $\mathrm{TaF}_{5}+\mathrm{LiF}$ & & $\mathrm{Pt}$ & & Smooth, coherent and dense layer & \\
\hline & & $\mathrm{TaF}_{5}+\mathrm{LiF}$ & BMP TFSA & NiTi & $200^{\circ} \mathrm{C}$ & $\begin{array}{l}\text { Ta subhalide on top of the } \\
\text { elemental } \mathrm{Ta}\end{array}$ & [12] \\
\hline & & $\mathrm{TaF}_{5}$ & BMP TFSA & $\mathrm{Au}$ & RT & $\begin{array}{l}\text { - Porous structure and cracks. } \\
\text { - Consist of elemental Ta and } \\
\text { some Ta oxides. }\end{array}$ & [13] \\
\hline & & \multirow{3}{*}{$\mathrm{TaF}_{5}$} & EMIM TFSA & & $\begin{array}{l}\text { RT - } \\
100^{\circ} \mathrm{C}\end{array}$ & No elemental Ta deposited & \multirow{3}{*}{ [14] } \\
\hline & & & PMIM TFSA & $\mathrm{Au}$ & $100^{\circ} \mathrm{C}$ & Cracked layer & \\
\hline & & & BMP TFSA & & $\begin{array}{l}100^{\circ} \mathrm{C} \\
120^{\circ} \mathrm{C}\end{array}$ & $\begin{array}{l}\text { - Cracked layer } \\
\text { - Galvanostatic obtained more } \\
\text { roundish grains than potentiostatic }\end{array}$ & \\
\hline & \multirow{6}{*}{$\mathrm{Ti}$} & $\mathrm{TiCl}_{4}$ & BMIM TFSA & $\mathrm{Au}$ & RT & Au-Ti surface alloying & [15] \\
\hline & & $\mathrm{TiCl}_{4}, \mathrm{TiF}_{4}, \mathrm{TiI}_{4}$ & EMIM TFSA & \multirow{3}{*}{$\mathrm{Au}$} & $\begin{array}{l}25- \\
200^{\circ} \mathrm{C}\end{array}$ & No deposit of elemental $\mathrm{Ti}$ & \multirow{3}{*}{ [16] } \\
\hline & & Ti-isopropanolate & $\mathrm{P}_{66614}$ TFSA & & $25-50^{\circ} \mathrm{C}$ & No deposit of elemental $\mathrm{Ti}$ & \\
\hline & & $\mathrm{TiCl}_{4}$ & BMP TFSA & & RT & Ultrathin layer of $\mathrm{Au}-\mathrm{Ti}$ & \\
\hline & & $\mathrm{TiCl}_{4}$ & EMIM TFSA & $\mathrm{GC}$ & RT & $\begin{array}{l}\text { Addition of pyrrole : } \\
\text { very smooth surface contained } \\
\text { very rich } \mathrm{Ti}\end{array}$ & [17] \\
\hline & & $\mathrm{TiO}_{2}$ & $\mathrm{AlCl}_{3}-\mathrm{BMIM} \mathrm{Cl}$ & $\begin{array}{l}\text { oxidized Ti } \\
\text { foil, } \mathrm{TiO}_{2} \\
\text { pellet }\end{array}$ & $70^{\circ} \mathrm{C}$ & Metallic Ti & [18] \\
\hline
\end{tabular}


Table 1. Continued

\begin{tabular}{|c|c|c|c|c|c|c|c|}
\hline Category & Element & Salt & Ionic Liquid & Substrate & Temp & Deposit & Ref \\
\hline \multirow{8}{*}{$\begin{array}{l}\text { Noble } \\
\text { Metals }\end{array}$} & \multirow{4}{*}{$\mathrm{Au}$} & $\mathrm{K}\left[\mathrm{Au}(\mathrm{CN})_{2}\right]$ & EMIM TFSA & $\begin{array}{l}\text { Si wafers } \\
\text { coated with } \\
200 \mathrm{~nm} \text { of } \\
\mathrm{Cu}\end{array}$ & RT & $\begin{array}{l}\text { - Micrometric acicular grains } \\
\text { - Without contamination of } \\
\mathrm{CN}^{-} \text {and organic additives }\end{array}$ & [19] \\
\hline & & $\mathrm{K}\left[\mathrm{Au}(\mathrm{CN})_{2}\right]$ & BMP TFSA & $\mathrm{Au}$ & RT & & [22] \\
\hline & & \multirow[b]{2}{*}{$\mathrm{HAuCl}_{4} \cdot 3 \mathrm{H}_{2} \mathrm{O}$} & \multirow[b]{2}{*}{ BMP DCA } & \multirow[b]{2}{*}{$\mathrm{Ni}$} & $\begin{array}{l}20^{\circ} \mathrm{C} \\
60^{\circ} \mathrm{C}\end{array}$ & $\begin{array}{l}\text { Discontinuous with poor } \\
\text { adherence }\end{array}$ & \\
\hline & & & & & $80^{\circ} \mathrm{C}$ & $\begin{array}{l}\text { Thin continuous layer of } \\
\text { nanoparticles covered by large } \\
\text { dendritic particles }\end{array}$ & [23] \\
\hline & \multirow[b]{2}{*}{$P d$} & $\mathrm{PdCl}_{2}-\mathrm{AgCl}$ & EMIM Cl-BF 4 & $\mathrm{Ni}$ & $35^{\circ} \mathrm{C}$ & $\begin{array}{l}\text { Compact deposits with nodular } \\
\text { grains and fine crystal }\end{array}$ & [24] \\
\hline & & $\mathrm{PdBr}_{4}{ }^{2-}, \mathrm{PdCl}_{4}{ }^{2-}$ & BMP TFSA & $\mathrm{Ni}$ & RT & $\begin{array}{l}\text { - Higher current density }(0.05 \\
\left.\mathrm{mA} \mathrm{cm}{ }^{2}\right): \text { powdery deposits. } \\
\text { - Lower current density }(0.01 \\
\left.\mathrm{mA} \mathrm{cm}{ }^{2}\right): \text { smooth deposits. }\end{array}$ & [26] \\
\hline & \multirow[b]{2}{*}{$\mathrm{Pt}$} & $\mathrm{H}_{2} \mathrm{PtCl}_{6}$ & $\begin{array}{l}\mathrm{BMIM} \mathrm{BF}_{4} \\
\text { BMIM PF }_{6}\end{array}$ & GC & RT & $\begin{array}{l}\text { - Uniform and fairly dense with } \\
\text { a size less than } 100 \mathrm{~nm} \text {. } \\
\text { - High catalytic performance. }\end{array}$ & [27] \\
\hline & & $\mathrm{H}_{2} \mathrm{PtCl}_{6}$ & $\mathrm{BMIM} \mathrm{PF}_{6}$ droplet & GC, ITO & RT & $\begin{array}{l}\text { - Uniform with a size ranging } \\
\text { from } 300 \text { to } 400 \mathrm{~nm} \text {. } \\
\text { - Excellent electrocatalytic } \\
\text { activity. }\end{array}$ & [28] \\
\hline
\end{tabular}

AFM images of $\mathrm{Pt}$ deposit in the ionic liquids showed uniform and fairly dense $\mathrm{Pt}$ nanoclusters with a size less than $100 \mathrm{~nm}$. An obvious difference appeared in $\mathrm{Pt}$ deposits obtained from $\mathrm{HClO}_{4}$ aqueous solution which has much bigger particle size. To examine the electrocatalytic properties, electrodeposited Pt films were tested for the electrooxidation of methanol and $\mathrm{Pt}$ films prepared in either BMIM $\mathrm{BF}_{4}$ or $\mathrm{BMIM} \mathrm{PF}_{6}$ ionic liquids exhibited high electrocatalytic current densities compared to that prepared in $\mathrm{HClO}_{4}$ aqueous solution. The authors concluded from the comparison of the size of Pt nanoclusters that the electrodeposition of $\mathrm{Pt}$ in the ionic liquids has a competitive edge judging from higher catalytic performance and utilization efficiency.

$\mathrm{Yu}$ et al. demonstrated a new method to electrodeposit Pt nanoparticles using ionic liquid droplet in aqueous solution to minimize the amount of expensive commercial ionic liquids. ${ }^{28}$ They found that water-immiscible ionic liquid is able to form a stable droplet on electrode surface with maintaining physical, chemical and electrochemical properties in aqueous solution. Based on the cyclic voltammogram in Fig. 7(a), the electrochemical window obtained

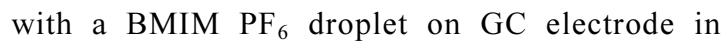
$0.1 \mathrm{M} \mathrm{KPF}_{6}$ solution is about $3 \mathrm{~V}$, which is wider than that obtained on bare $\mathrm{GC}$ electrode in the same aqueous solution but is narrower than that in pure ionic liquid solvent. Electrodeposition of $\mathrm{Pt}$ nanoparticles was carried out with a $\mathrm{BMIM} \mathrm{PF}_{6}$ droplet containing $0.1 \mathrm{M} \mathrm{H}_{2} \mathrm{PtCl}_{6}$ supported on $\mathrm{GC}$ or indium tin oxide (ITO) substrates in $0.1 \mathrm{M} \mathrm{KPF}_{6}$ solution at potential $-1.5 \mathrm{~V}$ vs. $\mathrm{Ag} / \mathrm{AgCl}$ for 500 seconds. By observing UV-vis spectra of the BMIM $\mathrm{PF}_{6}$ droplet containing $\mathrm{H}_{2} \mathrm{PtCl}_{6}$ before and after the addition of distilled water to a cell, the authors observed that $\mathrm{H}_{2} \mathrm{PtCl}_{6}$ was stably dissolved into the ionic liquid droplet and the transfer of $\mathrm{H}_{2} \mathrm{PtCl}_{6}$ from ionic liquid phase to distilled water was almost negligible during electrodeposition process. The SEM image of Fig. 7(b) shows that the morphology of deposited Pt nanoparticles was uniform with a size ranging from 300 to $400 \mathrm{~nm}$, larger than electrodeposited in pure BMIM $\mathrm{PF}_{6}$ solvent. This might result from the presence of the trace amount 
of water in the ionic liquid droplet which decreases its viscosity. ${ }^{29}$ Meanwhile, Pt nanoparticles deposited from the ionic liquid droplet had an excellent electrocatalytic activity toward the oxidation of methanol. This method can be suitable for electrodeposition of bimetal nanoparticles such as $\mathrm{Pt}-\mathrm{Ru}$ nanoparticles. Considering the economical usage of ionic liquids, this method can be a promising technique to electrodeposit metal nanoparticles at room temperature with minimum cost.

\section{Conclusions}

We have reviewed the application of ionic liquids to electrodeposition of metals, in particular, belonging to light, refractory and noble metals. Electrodeposition of light metals has a problem of dendrite formation in deposit layers. Addition of organic reagent might be necessary to obtain granular and fine particles. For example, a good morphology of Li deposits was obtained in PP13 TFSA with addition of VC. In the case of $\mathrm{Mg}$, the passivation of deposited layers by reaction of $\mathrm{Mg}$ metal with ionic liquids hinders the reversible deposition-dissolution process of $\mathrm{Mg}$. Although there was a report where smooth $\mathrm{Mg}$ films were successfully deposited on Ag substrate in BMIM $\mathrm{BF}_{4}$, it seems difficult to obtain the reversible deposition-dissolution process in ionic liquids. Imidazolium and pyrrolidinium-based ionic liquids with TFSA anion have been used to electrodeposit refractory metals. Due to their high reactivity, deposits of refractory metals have a tendency either to form subhalide species or to be re-oxidized. Ta deposit layers usually have a porous structure and cracked surface. Addition of $\mathrm{LiF}$ salt was proved to be an effective way to improve quality of $\mathrm{Ta}$ deposits resulting in smooth and dense layers. A very smooth Ti surface was obtained in EMIM TFSA by addition of pyrrole which might create nucleation sites in situ. Adsorption of $\mathrm{CN}^{-}$onto electrodeposited $\mathrm{Au}$ film should be avoided and there was a report where $\mathrm{Au}$ film deposited free of $\mathrm{CN}^{-}$contamination in EMIM TFSA. In the potentiostatic deposition of $\mathrm{Pd}-\mathrm{Ag}$ alloy, increasing $\mathrm{Pd}$ content in plating bath leads to nodular grains and fine crystal size while the galvanostatic electrodeposition of $\mathrm{Pd}$ with low current density produces smooth deposits. Ionic liquids with BMIM cation have been effective for the synthesis of uniform Pt nanoparticles with high electrocatalytic performance. Finally, we summarized the results discussed hitherto in Table 1.

\section{Acknowledgements}

This study was supported by the R\&D Center for Valuable Recycling (Global-Top Environmental Technology Development Program) funded by the Ministry of Environment. (Project No.: 11-A14-MR)

\section{References}

1. F. Andres, 'Ionic liquids: solvents for the electrodeposition of metals and semiconductors' Chem. Phys. Chem., 3, 144 (2002).

2. A. P. Abbott and K.J. McKenzie, 'Application of ionic liquids to the electrodeposition of metals' Phys. Chem. Chem. Phys., 8, 4265 (2006).

3. W. Simka, D. Puszczyk and G. Nawrat, 'Electrodeposition of metals from non-aqueous solutions' Electrochim. Acta, 54, 5307 (2009).

4. D. Aurbach, E. Zinigrad, Y. Cohen and H. Teller, 'A short review of failure mechanisms of lithium metal and lithiated graphite anodes in liquid electrolyte solutions' Solid State Ionics, 148, 405 (2002).

5. H. Sano, H. Sakaebe and H. Matsumoto, 'Observation of electrodeposited lithium by optical microscope in room temperature ionic liquid-based electrolyte' J. Power Sources, 196, 6663 (2011).

6. H. Ota, Y. Sakata, Y. Otake, K. Shima, M. Ue and J. Yamaki, 'Structural and functional analysis of surface film on $\mathrm{Li}$ anode in vinylene carbonate-containing electrolyte' J. Electrochem. Soc., 151, A1778 (2004).

7. Y. N. NuLi, J. Yang and P. Wang, 'Electrodeposition of magnesium film from $\mathrm{BMIM} \mathrm{BF}_{4}$ ionic liquid' Appl. Surf. Sci., 252, 8086 (2006).

8. P. Wang, Y. N. NuLi, J. Yang and Z. Feng, 'Mixed ionic liquids as electrolyte for reversible deposition and dissolution of magnesium' Surf. Coat. Tech., 201, 3783 (2006).

9. N. Amir, Y. Vestfrid, O. Chusid, Y. Gofer and D. Aurbach, 'Progress in nonaqueous magnesium electrochemistry' J. Power Sources, 174, 1234 (2007).

10. O. Shimamura, N. Yoshimoto, M. Matsumoto, M. Egashia and M. Morita, 'Electrochemical co-deposition of magnesium with lithium from quaternary ammoniumbased ionic liquid' J. Power Sources, 196, 1586 (2011).

11. S. Zein El Abedin, H. K. Farag, E. M. Moustafa, U. Welz-Biermann and F. Endres, 'Electroreduction of 
tantalum fluoride in a room temperature ionic liquid at variable temperatures' Phys. Chem. Chem. Phys., 7, 2333 (2005).

12. S. Zein El Abedin, U. Welz-Biermann and F. Endres, 'A study on the electrodeposition of tantalum on NiTi alloy in an ionic liquid and corrosion behaviour of the coated alloy' Electrochem. Commun., 7, 941 (2005).

13. N. Borisenko, A. Ispas, E. Zschippang, Q. Liu, S. Zein El Abedin, A. Bund and F. Endres, 'In situ STM and EQCM studies of tantalum electrodeposition from $\mathrm{TaF}_{5}$ in the air- and water-stable ionic liquid 1-butyl-1methylpyrrolidinium bis(trifluoromethylsulfonyl)amide' Electrochim. Acta, 54, 1519 (2009).

14. A. Ispas, B. Adolphi, A. Bund and F. Endres, 'On the electrodeposition of tantalum from three different ionic liquids with the bis(trifluoromethyl sulfonyl)amide anion" Phys. Chem. Chem. Phys., 12, 1793 (2010).

15. I. Mukhopadhyay, C. L. Aravinda, D. Borissov and W. Freyland, 'Electrodeposition of Ti from TiCl4in the ionic liquid 1-methyl-3-butyl-imidazolium bis(trifluoromethylsulfone)imide at room temperature: study on phase formation by in situ electrochemical scanning tunneling microscopy' Electrochim. Acta, 50, 1275 (2005).

16. F. Endres, S. Zein El Abedin, A. Y. Saad, E. M. Moustafa, N. Borissenko, W. E. Price, G. G. Wallace, D. R. MacFarlane, P. J. Newman and A. Bund, 'On the electrodeposition of titanium in ionic liquids' Phys. Chem. Chem. Phys., 10, 2189 (2008).

17. J. Ding, J. Wu, D. MacFarlane, W. E. Price and G. Wallace, 'Induction of titanium reduction using pyrrole and polypyrrole in the ionic liquid ethylmethyl-imidazolium bis(trifluoromethanesulphonyl) amide' Electrochem. Commun., 10, 217 (2008).

18. X.-Y. Zhang, Y.-X. Hua, C.-Y. Xu, Q.-B. Zhang, X.-B. Cong and N. Xu, 'Direct electrochemical reduction of titanium dioxide in Lewis basic AlCl3-1-butyl-3methylimidizolium ionic liquid' Electrochim. Acta, 56, 8530 (2011).

19. B. Bozzini, E. Tondo, A. Bund, A. Ispas and C. Mele, 'Electrodeposition of $\mathrm{Au}$ from [EMIm][TFSA] roomtemperature ionic liquid: An electrochemical and Surface-
Enhanced Raman Spectroscopy study' J. Electroanal. Chem. 651, 1 (2011).

20. B. Bozzini, L. D'Urzo and C. Mele, 'Electrodeposition of $\mathrm{Cu}$ from cyanoalkaline solutions in the presence of CPC and PEG' J. Electrochem. Soc., 152, C255 (2005).

21. B. Bozzini and A. Fanigliulo, 'Raman spectroscopy of organic species incorporated into electrodeposited gold layers' Trans. Inst. Met. Finish., 80, 25 (2002).

22. B. Bozzini, B. Busson, C. Humbert, C. Mele, P. Raffa and A. Tadjeddine, 'Investigation of Au electrodeposition from [BMP][TFSA] room-temperature ionic liquid containing $\mathrm{K}\left[\mathrm{Au}(\mathrm{CN})_{2}\right]$ by in situ two-dimensional sum frequency generation spectroscopy' $J$. Electroanal. Chem., 661, 20 (2011).

23. A.I. de Sá, S. Eugénio, S. Quaresma, C.M. Rangel and R. Vilar, 'Electrodeposition of gold thin films from 1butyl-1-methylpyrrolidinium dicyanamide $\mathrm{Au}^{3+}$ Solutions' Thin Solid Films, 519, 6278 (2011).

24. C-C. Tai, F-Y. Su and I-W. Sun, 'Electrodeposition of palladium-silver in a Lewis basic1-ethyl-3-methylimidazolium chloride-tetrafluoroborate ionic liquid' Electrochim. Acta, 50, 5504 (2005).

25. D. R. MacFarlane, J. Sun, J. Golding, P. Meakin and M. Forsyth, 'High conductivity molten salts based on the imide ion' Electrochim. Acta, 45, 1271 (2000).

26. Y. Bando, Y. Katayama and T. Miura, 'Electrodeposition of palladium in a hydrophobic1-n-butyl-1-methylpyrrolidinium bis(trifluoromethylsulfonyl)imide room-temperature ionic liquid' Electrochim. Acta, 53, 87 (2007).

27. P. He, H. Liu, Z. Li and J. Li, 'Electrodeposition of platinum in room-temperature ionic liquids and electrocatalytic effect on electro-oxidation of methanol' J. Electrochem. Soc., 152, E146 (2005).

28. P. Yu, J. Yan, J. Zhang and L. Mao, 'Cost-effective electrodeposition of platinum nanoparticles with ionic liquid droplet confined onto electrode surface as micromedia' Electrochem. Commun., 9, 1139 (2007).

29. J. A. Widegren, A. Laesecke and J.W. Magee, 'The effect of dissolved water on the viscosities of hydrophobic room-temperature ionic liquids' Chem. Commun., 1610 (2005). 